Check for updates

Cite this: RSC Adv., 2017, 7, 23234

Received 27th March 2017

Accepted 19th April 2017

DOI: $10.1039 / \mathrm{c} 7 \mathrm{ra03524a}$

rsc.li/rsc-advances

\section{A multi-functional iodoplumbate-based hybrid crystal: 1-propyl-4-aminopyridinium triiodoplumbate $\uparrow$}

\author{
Hai-Bao Duan, ID $\ddagger^{*}$ Shan-Shan Yu, $\$$ Shao-Xian Liu and Hui Zhang* \\ The temperature-dependent photoluminescence, dielectric and impedance spectra, as well as crystal \\ structures have been investigated for the iodoplumbate-based hybrid crystal, $\left[\mathrm{C}_{3}-\mathrm{Apy}\right]\left[\mathrm{Pbl}_{3}\right]$ (1) $\left(\mathrm{C}_{3}-\mathrm{Apy}^{+}\right.$ \\ = 1-propyl-4-aminopyridinium). Compound 1 in the room temperature (RT) contains $\left.[\mathrm{Pb}]_{3}\right]_{\infty}$ chains \\ formed by face-sharing distorted $\mathrm{Pbl}_{6}$ octahedral. In the low-temperature (LT) phase, the disordered \\ propyl groups in HT phase are partly ordered. 1 shows novel dielectric relaxation and thermochromic \\ luminescent properties.
}

The design of multi-functional molecular materials, especially those technologically useful properties are combined in a conventional inorganic solid with a continuous lattice, has recently attracted numerous of research attentions, because the combination of two cooperative properties in a material might result in new phenomena and novel applications. ${ }^{1-3}$ The versatility of molecular chemistry makes possible the design of new molecule-based materials that combine two (or more) physical properties. Thus, a possible approach to obtaining such materials is the so-called hybrid approach in which two-network solids are constructed through the self-assembly of two different molecular fragments where each molecular fragment furnishes distinct physical property. The haloplumbate-based hybrids have tunable structures from the discrete mononuclear or polynuclear species to infinite variety with higher dimensionality ${ }^{4-8}$ and a wide range of novel physical properties from optics ${ }^{9-12}$ to electronics. ${ }^{13-15}$ Some organic-inorganic hybrid crystal with interesting thermochromic luminescence properties have been reported..$^{16-19}$

In our previous studies, the octahedral $\left[\mathrm{PbI}_{6}\right]^{4-}$ building blocks were chosen for self-assembly with the different conformation counterions to give a variety of structure, ${ }^{4,11,20,21}$ and some of them exhibits multiple emissions or thermochromic luminescence properties. ${ }^{4,20,21}$ On the other hand, flexible organic counter cations can separate inorganic chain and further enhance their thermal stability. Basically, the dielectric

School of Environmental Science, Nanjing Xiaozhuang University, Nanjing 211171, P. R. China. E-mail: duanhaibao4660@163.com

$\dagger$ Electronic supplementary information (ESI) available: PXRD, TG, emission spectra in solids at room temperature, dielectric permittivity, impedance spectra and CIE coordinates. CCDC 1509582 and 1510132. For ESI and crystallographic data in CIF or other electronic format see DOI: 10.1039/c7ra03524a

\$ Hai-Bao Duan and Shan-Shan Yu contribute equally. response of the materials is due to the rotational or hopping moving of the polar molecules or ions and orientationally ordered states..$^{22-25}$ Thus, from the point of crystal engineering, introducing flexible organic counter cations into haloplumbatebased crystal lattices may obtain luminescence-dielectric multifunctional molecular materials. In this paper, we prepared and crystal structure of an iodoplumbate-based hybrid, [ $\left.\mathrm{C}_{3}-\mathrm{Apy}\right]$ $\left[\mathrm{PbI}_{3}\right](1)$ where $\mathrm{C}_{3}$-Apy ${ }^{+}=1$-propyl-4-aminopyridinium, which exhibits thermochromic luminescence and dielectric relaxation behavior.

The yellowish needle-shaped hybrid crystals of 1 were achieved by slowly evaporating the mixture of $\mathrm{PbI}_{2}, \mathrm{KI}$ and $\left[\mathrm{C}_{3}-\mathrm{Apy}\right]$ $\mathrm{Br}$ with molar ratio 1:10:1 in DMF at ambient temperature over 30 days and the yield is $c a .75 \%$ based on the reactant $\mathrm{PbI}_{2}$. The synthesized compound was insoluble in common organic solvents and water. The purity of hybrid was examined using elemental analyses for $\mathrm{C}, \mathrm{H}$ and $\mathrm{N}$ and powder X-ray diffraction technique (Fig. S1 $\uparrow$ ). Hybrid crystal $\mathbf{1}$ is thermally stable up to ca. $3500^{\circ} \mathrm{C}$ (Fig. $\left.\mathrm{S} 2 \dagger\right) . \S$

Compound $\mathbf{1}$ in the room temperature (RT) crystallizes in the orthorhombic space group Pnma, the asymmetric unit contains one crystallographically distinct $\mathrm{Pb}^{2+}$ ions, two different $\mathrm{I}^{-}$ anions and half $\mathrm{C}_{3}-\mathrm{Apy}^{+}$cation (Fig. 1a). The cell parameter are analogue to our previous reported $\left[\mathrm{C}_{2}-\mathrm{Apy}\right]\left[\mathrm{PbI}_{3}\right]$ compound, ${ }^{26}$ however, the packing structure and physical properties of the

$\S$ Crystal data for compound 1 at rome temperature (CCDC 1509582), $\mathrm{C}_{16} \mathrm{H}_{26} \mathrm{I}_{6} \mathrm{~N}_{4} \mathrm{~Pb}_{2}, M=1450.2, a=7.8748(5) \AA, b=10.4050(8) \AA ⿻$ А $c=19.3554(17)$ $\AA, \alpha=\beta=\gamma=90^{\circ}, V=1585.9(5) \AA^{3}, Z=2, D_{\mathrm{c}}=3.307 \mathrm{~g} \mathrm{~cm}^{-3}, F(000)=$ $1264.0, R_{\text {int }}=0.1129, R_{1}=0.0832, \mathrm{w} R_{2}=0.0949$. Single crystal diffraction data for 1 at room temperature and $120 \mathrm{~K}$ (CCDC 1510132) were collected on a Siemens SMART-CCD diffractometer with graphite monochromatic Mo K $\alpha$ radiation $(\lambda=0.71073 \AA)$. The structures were solved by direct method and refined on F2 using full matrix least-squares method with SHELXTL. ${ }^{31}$ Anisotropic thermal parameters were refined for the non-hydrogen atoms. The hydrogen atoms were placed at calculated positions. 
(a)

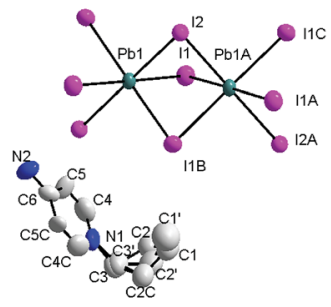

(b)

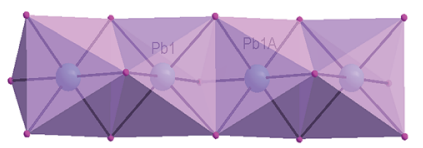

(c)

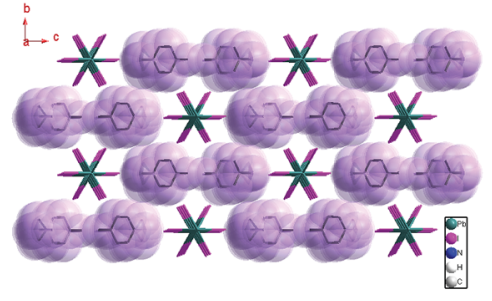

(d)

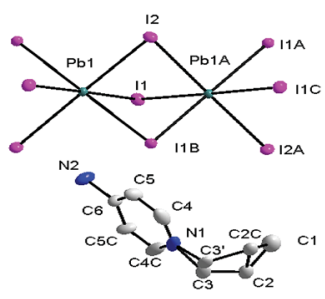

Fig. 1 (a) Molecular structure of 1 at $293 \mathrm{~K}$ with non-hydrogen atom labeling thermal ellipsoids drawn at the $50 \%$ probability level (the symmetric codes: $A=1.5-x, 1.5-y, z ; B=1-x,-y, 1-z ; C=2.5-$ $x, 1+y, 2.5-z$ ); (b) face-sharing octahedral chain of $\left[\mathrm{Pbl}_{3}\right]^{\infty}$; (c) packing diagram viewed along the a-axis direction and (d) molecular structure of 1 at $120 \mathrm{~K}$ with non-hydrogen atom labeling thermal ellipsoids drawn at the $50 \%$ probability level.

two compounds are different. $\mathrm{Pb}$ atom is coordinated with six $\mathrm{I}^{-}$ from two types $\mathrm{I}^{-}$to form the slightly distorted $\mathrm{PbI}_{6}$ octahedron. The $\mathrm{Pb}(1)-\mathrm{I}(1)$ bond length is $3.204 \AA$, and $\mathrm{Pb}(1)-\mathrm{I}(2)$ bond length is $3.256 \AA$, all within the van der Waals contact limit. Two of $\mathrm{I}^{-}$anions have $\mu_{2}$ connections model linking each $\mathrm{Pb}^{2+}$ ions. Thus, each $\mathrm{PbI}_{6}$ octahedron shares faces with other two $\mathrm{PbI}_{6}$ octahedron forming an infinite one dimension (1D) chain (Fig. 1b). The cations adopt the bent conformation, alkyl chain slightly disrupted close to the pyridyl ring with an almost completely trans-planar conformation. It is noted that the alkyl chains exhibit heavily disordered in RT phase although the equivalent and anisotropic displacement factors in $\left[\mathrm{PbI}_{3}\right]^{-}$ inorganic moieties and the 4- $\mathrm{NH}_{2} \mathrm{Py}$ moieties are comparable to those at LT phase. The $\mathrm{C}_{3}-\mathrm{Apy}^{+}$cation interacted with each other through propyl-propyl interactions. Along the $a$-axis direction, these interaction lead to information of $1 \mathrm{D}$ channel, and $\left[\mathrm{PbI}_{3}\right]^{-}$ is resided in the channel (Fig. 1c). The channel size is about $14.01 \times 18.67 \AA^{2}$. The crystal structure of 1 at $120 \mathrm{~K}$ (in LT phase) is quite analogous to that at RT phase. In LT phase, the cell parameters and packing structure is almost not changed. From 120 to $293 \mathrm{~K}$, the $a$-, $b$ - and $c$-axes shrinks respectively by $0.89 \%, 0.96 \%$, and $1.24 \%$, and the cell volume shrinks by $3.21 \%$. However, the displacement parameters in propyl chain are obviously small than those at $293 \mathrm{~K}$. The $\mathrm{Pb}^{2+}$ ions also are all situated in a distorted octahedral coordination environment and the $\mathrm{Pb}-\mathrm{I}$ distances is similar with $\mathrm{RT}$ phase. The most remarkable change is that the structurally disordered propyl group in the HT phase becomes partly ordered at $120 \mathrm{~K}$ (Fig. 1d).

Frequency dependences of $\varepsilon^{\prime}$ and $\tan (\delta)=\varepsilon^{\prime \prime} / \varepsilon^{\prime}$ are shown in Fig. S3, S4 $\dagger$ and 2 for 1 in the temperature range $10-130{ }^{\circ} \mathrm{C}$. At $f$ $<10 \mathrm{~Hz}$, there is a sharp increase in the $\varepsilon^{\prime}$ data with decreasing (a)

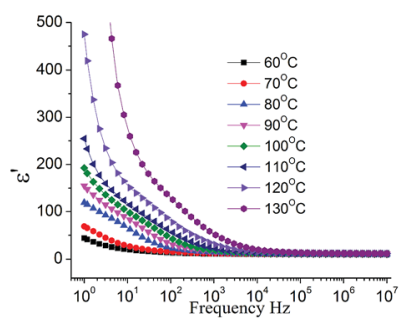

(c)
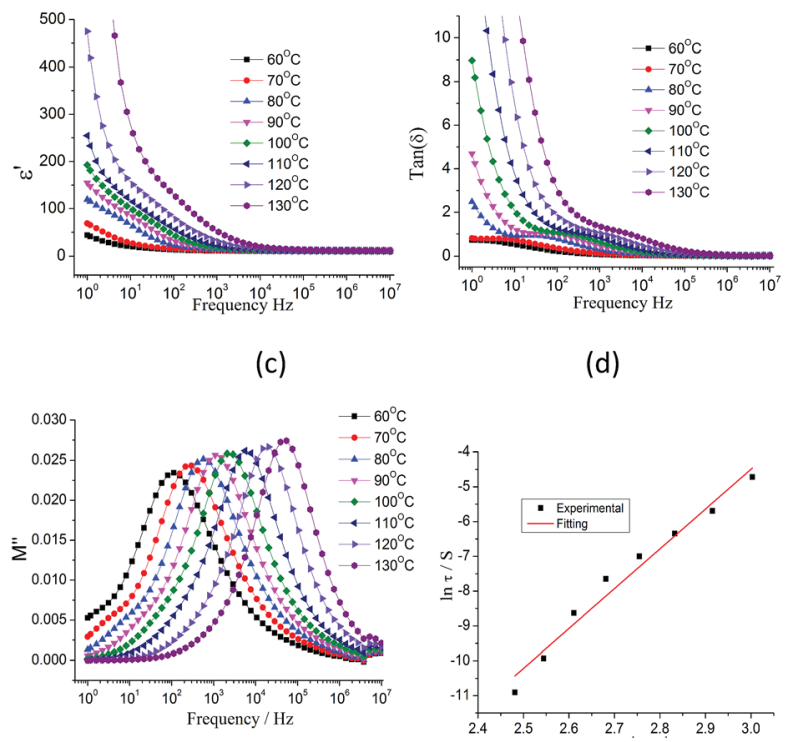

(d)

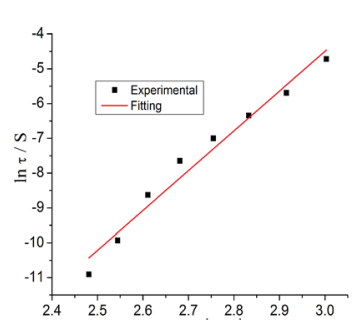

(e)

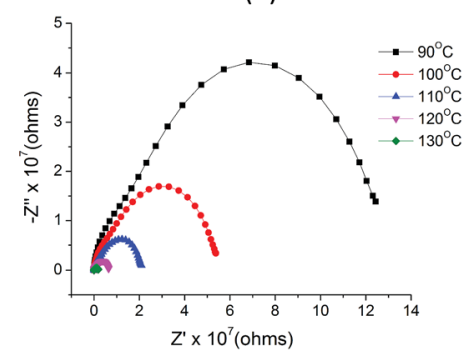

Fig. 2 (a) and (b) Frequency dependencies of the $\varepsilon^{\prime}$ and $\tan (\delta)$ of 1 in the $60-130^{\circ} \mathrm{C}$ temperature range, respectively; (c) imaginary parts of the complex modulus ( $\left.\mathrm{M}^{\prime \prime}\right)$ versus frequency; (d) plots of In $\tau$ vs. 1000/T for the relaxation and (e) complex impedance of 1 at selected temperatures.

frequency that is attributed to space charge polarization associated with sample-electrode interface polarization and the $\varepsilon^{\prime}$ value of low frequency gradually decrease with temperature decreasing (Fig. 2a). Where thermal motion of dipole units almost be suppressed in the low temperature. At $f>100 \mathrm{~Hz}$, the curves of dielectric loss $\tan (\delta)-f$ (Fig. 2b) show a wide rounded maximum in the selected temperature, attributed to the polarization arising from the dielectric relaxation of the lattice. However, it is difficult to analyze the frequency dependence of $\varepsilon^{\prime}$ and $\tan (\delta)$ because a strong low-frequency dispersion appears when the temperature increased. Here, we use dielectric modulus to analyze the dielectric relaxation processes in $\mathbf{1}$, which can significantly reduce electrode polarization effect at the low-frequency. ${ }^{27,28}$ The electric modulus is calculated by eqn (1). ${ }^{29,30}$

$$
M^{*}(\omega)=\frac{1}{\varepsilon^{*}(\omega)}=\frac{\varepsilon^{\prime}+j \varepsilon^{\prime \prime}}{\varepsilon^{\prime 2}+\varepsilon^{\prime \prime^{2}}}=M^{\prime}+j M^{\prime \prime}
$$

where $M^{\prime}$ and $M^{\prime \prime}$ are the real and imaginary parts of the complex modulus $M^{*}$, respectively. As shown in Fig. 2c, compound 1 only exhibits one relaxation peak for $M^{\prime \prime}$ in the 
selected temperature, which is different from compound $\left[\mathrm{C}_{2}\right.$ Apy $]\left[\mathrm{PbI}_{3}\right]$, in here two step dielectric response were observed. The peak shift to low frequency region with the temperature increasing for $\mathbf{1}$. The activation energy $\left(E_{\mathrm{a}}\right)$ of the relaxation can be calculated from Arrhenius law as our described previously. ${ }^{4}$ The best fits giving the $\tau_{0}=3.48 \times 10^{-13} \mathrm{~s}$ and $E_{\mathrm{a}}=0.835 \mathrm{eV}$ in the temperature range $60-130{ }^{\circ} \mathrm{C}$ (Fig. $2 \mathrm{~d}$ ). The value of $E_{\mathrm{a}}$ for 1 is larger than compound $\left[\mathrm{C}_{2}-\mathrm{Apy}\right]\left[\mathrm{PbI}_{3}\right]$, which can be ascribe to the different packing structure and interaction between the cation and inorganic chain. This step dielectric relaxation arise from the molecular dipole motion, and can be attribute to alkyl chain swing motion. We further analyze the impedance spectra of 1 in the temperature range $60-130{ }^{\circ} \mathrm{C}$ (Fig. 2e and S5 $\dagger$ ). The plot shows a single semicircle related to bulk effects, which is characteristic for electronic conductors. The center of these semicircles is depressed below the real axis, indicating nonDebye relaxation process. Ionic conductivity can be calculated from the impedance fitting curves. The temperature dependent dc are shown in Fig. $66, \uparrow$ which shows linear relationship in the temperature range of $60-130{ }^{\circ} \mathrm{C}$, and the activation energy $\left(E_{\mathrm{a}}\right)$ was estimated to be $0.538 \mathrm{eV}$, this value is small than obtained from the dielectric relaxation $(0.835 \mathrm{eV})$, indicating that dielectric relaxation at is not caused by dc conduction.

The absorption spectra of $\mathbf{1}$ in the solid state are shown in Fig. 3a. The shape of broad absorption band is similar with compound $\left[\mathrm{C}_{2}-\mathrm{Apy}\right]\left[\mathrm{PbI}_{3}\right]$. It contains a broad band below $350 \mathrm{~nm}$ and a narrow band centered around $385 \mathrm{~nm}$. However, the emission spectra of two compounds are very different. The room temperature photoluminescence (PL) spectra of 1 shows a weak broad emission band extending from $530 \mathrm{~nm}$ to $780 \mathrm{~nm}$ on the excitation of $\lambda_{\mathrm{ex}}=335 \mathrm{~nm}$ (Fig. $\mathrm{S} 7 \dagger$ ). The observed broad (a)

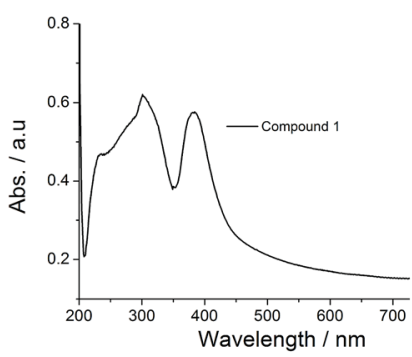

(c)

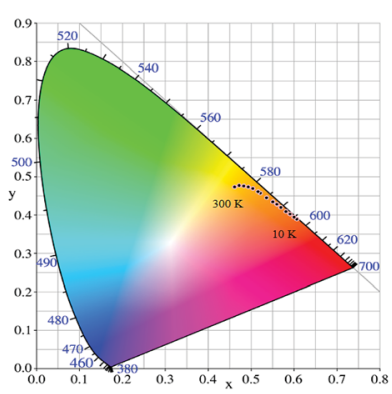

(b)

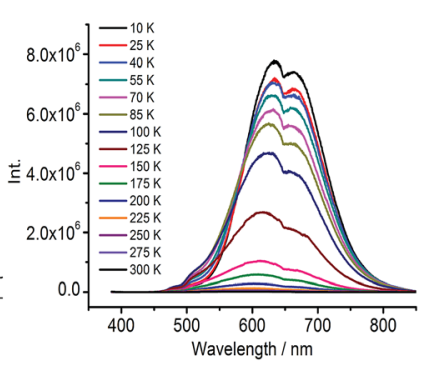

\section{Acknowledgements}

The authors thanks National Nature Science Foundation of China and Natural Science Training Foundation of Nanjing Xiaozhuang University for their financial support (grant No: 21201103, 21301093 and 2016NXY12).

\section{Notes and references}

1 E. Coronado, J. R. Galán-Mascarós, C. J. Gómez-García and V. Laukhin, Nature, 2000, 408, 447; M. Clemente-León, E. Coronado, M. López-Jordá, G. M. Espallargas, A. Soriano-Portillo and J. C. Waerenborgh, Chem.-Eur. J., 2010, 16, 2207.

2 J.-M. Rueff, J.-F. Nierengarten, P. Gilliot, A. Demessence, O. Cregut, M. Drillon and P. Rabu, Chem. Mater., 2004, 16, 2933; M. Gonidec, F. Luis, Á. Vílchez, J. Esquena, D. B. Amabilino and J. Veciana, Angew. Chem., Int. Ed., 2010, 49, 1623.

Fig. 3 (a) UV-Vis absorption spectrum at solid state; (b) temperature dependent emission spectra at solid state and (c) CIE chromaticity diagram showing the fluorescence color of 1 at selected temperatures.
3 M. E. Itkis, X. Chi, A. W. Cordes and R. C. Haddon, Science, 2002, 296, 1443. 
4 Y. B. Tong, L. T. Ren, H. B. Duan, J. L. Liu and X. M. Ren, Dalton Trans., 2015, 44, 17850.

5 Z. Tang and A. M. Guloy, J. Am. Chem. Soc., 1999, 121, 452.

6 Z. J. Zhang, S. C. Xiang, Y. F. Zhang, A. Q. Wu, L. Z. Cai, G. C. Guo and J. S. Huang, Inorg. Chem., 2006, 45, 1972.

7 J. J. Liu, Y. F. Guan, C. Jiao, M. J. Lin, C. C. Huang and W. X. Dai, Dalton Trans., 2015, 44, 5957.

8 L. L. Mao, H. Tsai, W. Nie, L. Ma, J. Im, C. C. Stoumpos, C. D. Malliakas, F. Hao, M. R. Wasielewski, A. D. Mohite and M. G. Kanatzidis, Chem. Mater., 2016, 28, 7781.

9 E. R. Dohner, E. T. Hoke and H. I. Karuadasa, J. Am. Chem. Soc., 2014, 136, 1718.

10 C. Wehrenfenging, M. Liu, H. J. Snaith, M. B. Johnston and L. M. Herz, J. Phys. Chem. Lett., 2014, 5, 1300.

11 J. I. Fujisawa and T. Ishihara, Phys. Rev. B: Condens. Matter Mater. Phys., 2004, 70, 113203.

12 G. N. Liu, J. R. Shi, X. J. Han, X. Zhang, K. Li, T. Zhang, Q. S. Liu, Z. W. Zhang and C. C. Li, Dalton Trans., 2015, 44, 12561.

13 W. S. Yang, J. H. Noh, N. J. Jeon, Y. C. Kim, S. Ryu, J. Seo and S. I. Seok, Science, 2015, 348, 1234.

14 M. Liu, M. B. Johnston and H. J. Snaith, Nature, 2013, 501, 395.

15 G. Xing, N. Mathews, S. Sun, S. S. Lim, Y. M. Lam, M. Grätzel, S. Mhaisalkar and T. C. Sum, Science, 2013, 18, 344.

16 Z. H. Yan, X. Y. Li, L. W. Liu, S. Q. Yu, X. P. Wang and D. Sun, Inorg. Chem., 2016, 55, 1096.

17 S. Yuan, Y. K. Deng and D. Sun, Chem.-Eur. J., 2014, 20, 10093.
18 H. Y. Zhuo, H. F. Su, Z. Z. Cao, W. Liu, S. A. Wang, L. Feng, G. L. Zhuang, S. C. Lin, M. Kurmoo, C. H. Tung, D. Sun and L. S. Zheng, Chem.-Eur. J., 2016, 22, 17619.

19 Z. Wang, G. L. Zhuang, Y. K. Deng, Z. Y. Feng, Z. Z. Cao, M. Kurmoo, C. H. Tung and D. Sun, Inorg. Chem., 2016, 55, 4757.

20 H. B. Duan, H. R. Zhao, X. M. Ren, H. Zhou, Z. F. Tian and W. Q. Jin, Dalton Trans., 2011, 40, 1672.

21 H. B. Duan, S. S. Yu, Y. B. Tong, H. Zhou and X. M. Ren, Dalton Trans., 2016, 45, 4810.

22 Z. Y. Du, Y. Z. Sun, S. L. Chen, B. Huang, Y. J. Su, T. T. Xu, W. X. Zhan and X. M. Chen, Chem. Commun., 2015, 51, 15642.

23 P. C. Guo, T. Y. Chen, X. M. Ren, W. H. Ning and W. Q. Jin, New J. Chem., 2014, 38, 2254.

24 F. K. He, C. Yuan, K. Li, S. Diao, K. K. Jin, J. J. Wang, J. W. Tong, J. Ma and Q. Fang, RSC Adv., 2013, 3, 23128.

25 S. S. Yu, S. X. Liu and H. B. Duan, RSC Adv., 2015, 44, 20822.

26 H. B. Duan, S. S. Yu, S. X. Liu and H. Zhang, Dalton Trans., 2017, 46, 2220.

27 J. Świergiel and J. Jadizyn, Ind. Eng. Chem. Res., 2011, 50, 11935.

28 J. Jadizyn and J. Świergiel, Ind. Eng. Chem. Res., 2012, 51, 807.

29 W. Trigui, A. Oueslati, I. Chaabane, G. Corbel and F. Hlel, Appl. Phys. A, 2015, 119, 673.

30 M. F. Mostafa and A. S. Atallah, Phys. Lett. A, 1999, 264, 242.

31 G. M. Sheldrick, SHELX-97, Program for the refinement of crystal structure, University of Göttingen, Germany, 1997. 